\title{
Cis-and Trans-Gnetin H from Paeonia suffruticosa Suppress Inhibitor Kappa B Kinase Phosphorylation in LPS-Stimulated Human THP-1 Cells
}

Authors: Hyo S Park ${ }^{\mathrm{a}}$, Eric J Vick ${ }^{\mathrm{a}}$, Ying Gao ${ }^{\mathrm{a}}$, Chunnian $\mathrm{He}^{\mathrm{b}}$, Nadin Marwan Almosnid ${ }^{\mathrm{a}}$, Mary Farone $^{\mathrm{a}}$, Anthony L Farone ${ }^{\mathrm{a}}$

First author: Hyo Sim Park

Middle Tennessee State University, 1301 East Main Street, Murfreesboro, Tennessee 37132, $\mathrm{USA}^{\mathrm{a}}$

Email address: hsp2g@mtmail.mtsu.edu

Eric J. Vick

Middle Tennessee State University, 1301 East Main Street, Murfreesboro, Tennessee 37132, USA

Email address: ejvick@gmail.com

Ying Gao

Middle Tennessee State University, 1301 East Main Street, Murfreesboro, Tennessee 37132, USA

Email address: ying.gao@mtsu.edu

Chunnian $\mathrm{He}$

Institute of Medicinal Plant Development, Chinese Academy of Medical Science, No. 151

Malianwa, North Road, Haidian District, Beijing 100193, P.R. China ${ }^{\mathrm{b}}$

Email address: cnhe@implad.cn

Nadin Marwan Almosnid

Middle Tennessee State University, 1301 East Main Street, Murfreesboro, Tennessee 37132, USA 
Email address: nma2v@mtmail.mtsu.edu

Mary Farone

Middle Tennessee State University, 1301 East Main Street, Murfreesboro, Tennessee 37132, USA

Email address: mary.farone@mtsu.edu

Corresponding author: Anthony L. Farone

Middle Tennessee State University, 1301 East Main Street, Murfreesboro, Tennessee 37132, $\mathrm{USA}^{\mathrm{a}}$

Email address:anthony.farone@mtsu.edu

\begin{abstract}
Ethnopharmacological relevance: The inflammatory response is an important mechanism in host defense; however, overstimulation and chronic inflammation are involved in many important human diseases. Currently, tumor necrosis factor-alpha blockers such as infliximab and adalimumab along with methotrexate are used in cases of severe and chronic disease. However, there are severe side effects and limitations associated withthese treatments. Cis- and transgnetin $\mathrm{H}$ are compounds isolated from the seeds ofPaeonia suffruticosa, a medicinal plant used in traditional Chinese medicine for thetreatment of many conditions, including inflammatory diseases. In this study, we investigated possible anti-inflammatory mechanisms of cis- and transgnetin H against LPS-stimulatedhuman THP-1 cells.

Material and Methods: PMA-differentiated THP-1 cells were pretreated with increasing concentrations of cis- and trans-gnetin Hwith or without LPS. Following treatment, cytotoxicity and the TNF- $\alpha$, IL- $1 \beta$, and IL-8 response were measured. We also characterized the nuclear translocation of NF- $\kappa \mathrm{B}$ subunitp65 (RelA)by immunofluorescence and then investigated NF- $\kappa \mathrm{B}$ activation by measuring the phosphorylation of NF- $\kappa B$ mediators, IKK $-\beta$, I $\kappa \mathrm{B} \alpha$, and p 65 by western blotting.
\end{abstract}


Results: We found that cis- and trans-gnetin H significantly inhibited the cytokine responsein a concentration-dependent manner without affecting cell viability. Cis- and trans-gnetin Heffectively inhibited nuclear translocation of p65 and phosphorylation of IKK- $\beta$, I $\kappa$ B $\alpha$, and p65. While both compounds showed promising anti-inflammatory effects, trans-gnetin Hwas determined to be more effective in suppressing cytokine responses.

Conclusion: We demonstrated that cis- and trans-gnetin H suppress cytokine response in LPSstimulated THP-1 cells by preventingactivation of key signaling molecules, IKK- $\beta$, I $\kappa \mathrm{B} \alpha$, and p65, involved in the NF- $\mathrm{BB}$ pathway and suggest the use of cis-and trans-gnetin $\mathrm{H}$ in potential therapies for conditions and diseases associated with chronic inflammation.

Key words: Gnetin H, Paeonia suffruticosa, Anti-inflammatory, Inhibitor kappa B kinase, Nuclear translocation, Traditional Chinese Medicine

\section{Introduction}

Control of inflammation is critical for treatment of autoimmune diseases and chronic inflammatory diseases and is achieved with steroidal and nonsteroidal anti-inflammatory drugs (NSAIDS), which comprise the major classes of anti-inflammatory compounds. NSAIDS have become one of the commonly used medications, although the negative effects of NSAIDS have raised concerns over awareness of their side effects such as gastrointestinal bleeding, hepatic and renal toxicity, and cardiovascular events (Aminoshariae et al., 2016; Bozimowski,

2015).Recently, monoclonal antibodies and fusion proteins have been developed to treat chronic inflammation (Thalayasingam and Isaacs, 2011); however, they can cause severe side effects, such as allergic reactions, malignancies, increased risk of infection, and stroke, and are limited to severe inflammatory diseases such as rheumatoid arthritis and ankylosing spondylitis (Bezalel et al., 2012; Bjarnason et al., 1993; Bongartz et al., 2006; Diamantopoulos et al., 2013). Another reason for the interest in new anti-inflammatory therapeutics is the high cost of treatment; the associated cost of inflammatory conditions well exceeds the cost associated with cancer treatment. It is increasingly recognized that inflammation contributes to many pathogenic processes, but the current classes of inflammatory drugs also have substantial side effects; this drives the search for safer and less expensive alternatives. Recently, more attention has been given to traditional Chinese medicine (TCM) herbal ingredients that have been used to treat 
inflammatory diseases (Wang et al., 2013). TCM has received more attention because of its safety and efficacy, fewer side effects, lower cost, and potential use as an adjunct to Western medicine (Zhao et al., 2014). Providing a molecular basis for active ingredients found in herbal medicines further enhances their use in the treatment of serious conditions and diseases associated with chronic inflammation.

Activated macrophages produce biologically active cytokines such as tumornecrosis factor alpha (TNF- $\alpha$ ), through the nuclear factor kappa B (NF- $\kappa$ B)intracellular signaling pathway (Yamamoto and Gaynor, 2001a). This pathway involves numerous factors and kinases that are regulated by phosphorylation. Transcription factors that regulate the inflammatory response are sequestered in the cytoplasm by inhibitor molecules, inhibitor kappa B alpha (I $\mathrm{KB} \alpha$ ), which regulates NF-

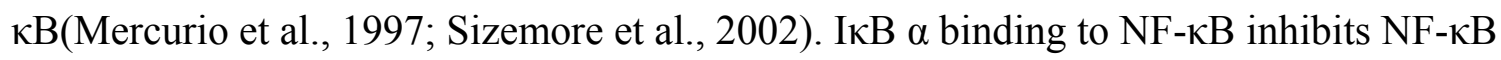
transactivation, translocation, and promoter binding (Ganchi et al., 1992). When the necessary

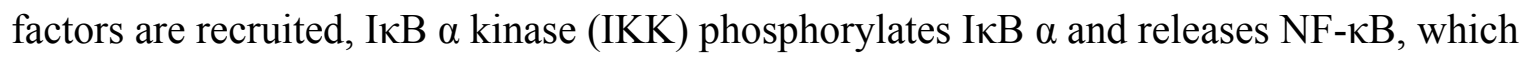
ultimately translocates to the nucleus and promotes the transcription and release of inflammatory genes, including the biologically active cytokines TNF- $\alpha$ and proinflammatory interleukins (IL). Released cytokines induce biological effects, such as chemotaxis, vasodilation, cell proliferation, and cell differentiation. TNF- $\alpha$ has been found to be the critical proinflammatory cytokine released by various cell types to initiate the amplification of inflammation (Aggarwal, 2003). Current therapeutics using corticosteroids, monoclonal antibodies, and recombinant proteins suppress inflammation by preventing leukocyte activation or neutralizing TNF- $\alpha$.

Cis- and trans-gnetin $\mathrm{H}$ compounds are oligostilbenes that have been isolated from the herbal plant Paeonia suffruticosa, an important medicinal plant that has been used in TCM for thousands of years. Paeonia suffruticosa has been widely used as an analgesic, anti-anaphylactic, anti-oxidative, and anti-inflammatory agent (He et al., 2010; Hu et al., 2010; Oh et al., 2003).The seeds of the plant are used in traditional medicine throughout East Asia to treat atherosclerosis, inflammation, infection, and cutaneous diseases (Choi et al., 2012; Gao et al., 2015).Cis- and trans-gnetin $\mathrm{H}$ compounds are isomers of resveratrol trimers; however, they differ in their olefinic moiety between C-7'/C8' (Figures 1A and 1B). Resveratrol is a stilbene produced by numerous types of plants and has anti-cancer and anti-inflammatory effects that have been 
studied extensively (Aggarwal et al., 2004; Manna et al., 2000). However, the anti-inflammatory mechanism of cis-and trans-gnetin $\mathrm{H}$ has not been fully described.

In this study, we sought to determine if the oligostilbenescis-and trans-gnetin Hcould suppress inflammatory cytokines and the NF- $\kappa$ B pathway in PMA-differentiated human THP-1 cells stimulated with lipopolysaccharide. The THP-1 cell line has been used as an in vitro model to investigate roles for monocytes and macrophages in innate immunity, including their responses to various stimulants such as bacterial lipopolysaccharides (Chanput et al., 2014). THP-1 cells express MD2, CD14, and MYD88 genes as well as genes associated with inflammatory pathways, making the cell line an excellent model to study cytokine response by LPS stimulation. Using THP-1 cells, we first examined the expression of the proinflammatory cytokines TNF- $\alpha$, IL-1 $\beta$, and IL-8 and then assessed the key NF- $\mathrm{B}$ inhibitory mechanism by measuring the nuclear translocation of the activated NF- $\kappa B$ transcription factor, $\mathrm{p} 65$. We further examined the expression of the activated/phosphorylated upstream kinase, IKK- $\beta$, and regulatory factor,IкB

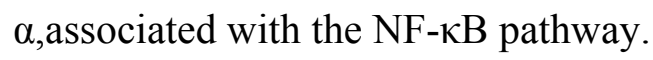

\section{Materials and Methods}

\subsection{Reagents}

THP-1 cells (ATCC, TIB 202) were purchased from the American Type Culture Collection (Manassas, VA, USA). The $\gamma$-irradiated Salmonella enterica serotype Typhimurium lipopolysaccharide (LPS) was purchased from Sigma-Aldrich (catalog number L6143, St. Louis, MO, USA). Dexamethasone, 3-(4-methylphenylsulfonyl)-2-propenenitrile (Bay 11-7082), dimethyl sulfoxide (DMSO), phorbol 12-myristate 13-acetate (PMA), and RPMI 1640 culture media were purchased from Sigma-Aldrich (St. Louis, MO, USA). Fetal bovine serum (FBS), enhanced chemiluminescence luminol (ECL) substrate, 100X penicillin/streptomycin solution, SDS-PAGE gels, and nitrocellulose membranes were obtained from Fisher Scientific (Pittsburgh, PA, USA). Alamar Blue was purchased from Life Technologies (Grand Island, NY, USA), ELISA kits and associated reagents were obtained from R\&D Systems (Minneapolis, MN, USA).

CellTiter-Glo® Luminescent assay was purchased from Promega (Madison, WI, USA). Bovine serum albumin (BSA) was obtained from EMD Millipore (Billerica, MA, USA). Cellomics NF- 
$\kappa \mathrm{B}$ and BCA kits were purchased from Thermo Scientific (Waltham, MA, USA). Antibodies for the western blot analysis were purchased from Cell Signaling Technology (Denver, MA, USA).

\subsection{Plant Material}

Seeds of Paeonia suffruticosa were collected in Tongling, Anhui Province, P.R. China, and a voucher specimen has been deposited in the Seed Resource Bank of the Institution of Medicinal Plant Development, Chinese Academy of Medical Science and Peking Union Medical College(Gao et al., 2015).

\subsection{Extraction and Isolation of Cis- and Trans-Gnetin H}

Cis- and trans-gnetin $\mathrm{H}$ were extracted and isolated from the dried seeds of Paeonia suffruticosa as described previously (He et al., 2010). Briefly, the dried seeds were extracted with ethanol for $24 \mathrm{~h}$ at room temperature and then subfractionated using water, cyclohexane, chloroform, and ethyl acetate. Cis- and trans-gnetin $\mathrm{H}$ were purified from the ethyl acetate extract, further fractionated using chloroform-methanol elution followed by ODS-A C18 reversed-phase silica gel $(\mathrm{MeOH}-\mathrm{H} 2 \mathrm{O})$ and then purified by Sephadex LH-20 column chromatography. The compounds were suspended in DMSO to yield the desired concentration and stored at $4{ }^{\circ} \mathrm{C}$.

\subsection{Maintenance and Differentiation of the THP-1 Cell Line}

THP-1 cells were maintained in RPMI 1640 medium supplemented with 10\% complementinactivated FBS and $1 \%$ penicillin/streptomycin solution(complete culture medium) at $37^{\circ} \mathrm{C}$ with $5 \% \mathrm{CO}_{2}$. The cells were adjusted to the desired concentrations for each experiment bycentrifugation at $500 \mathrm{xg}$ for $5 \mathrm{~min}$ and resuspension in complete culture medium with $100 \mathrm{nM}$ PMA. Cell concentrations wereadjusted to $5 \times 10^{5}$ cells $/ \mathrm{ml}$ for most assays other than NF- $\mathrm{BB}$ nuclear translocation assay which used $2.5 \times 10^{5}$ cells $/ \mathrm{ml}$. Cells were seeded onto 96-, 24-, or $12-$ well plates and incubated for 48 to $72 \mathrm{~h}$ to allow for differentiation. The cells were washed with serum-free RPMI 1640 medium before each experiment to remove undifferentiated cells.

\subsection{Assessment of Cell Viability and Cytokine Response by ELISA}

Differentiated THP-1 cells were pretreated with various concentrations of cis-gnetin H, transgnetin $\mathrm{H}$, or $1 \mu \mathrm{M}$ dexamethasone for $1 \mathrm{~h}$ and then stimulated with $20 \mathrm{ng} / \mathrm{ml}$ LPS for $4 \mathrm{~h}$. 
Dexamethasone is a synthetic glucocorticoid that suppresses cytokine responses and was used as a positive control(Abraham et al., 2006). Supernatants were collected for human cytokine ELISAs and the manufacturer's protocol was followed to assess the cytokine response.For remaining cells, relative cell viability was assessed as an internal control using Alamar Blue or CellGlow ${ }^{\circledR}$ Luminescent Assays. For Alamar Blue assays, cells were incubated with 1X Alamar Blue reagent overnight and viability was evaluated by measuring relative fluorescent units (RFU) on the SpectraMax M2e microplate reader (Molecular Devices Inc., Sunnyvale, CA, USA) at Ex $560 \mathrm{~nm}$ and Em $590 \mathrm{~nm}$. For CellTiter-Glo® luminescent assays, treated cells were lysed with the CellGlow reagent and the relative luminescence was measured using the SpectraMax M2e microplate reader as recommended by the manufacturer's protocol. Concentrations of DMSO (vehicle control) at $0.07,0.13,0.25,0.5$, and $1 \%$ were assessed for their potential effects on cytokine response as well as cell viability.

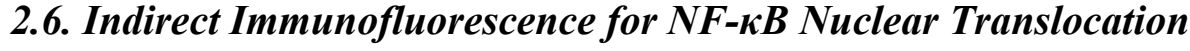

Differentiated THP-1 cells were pretreated with $50 \mu \mathrm{M}$ cis-gnetin $\mathrm{H}$, trans-gnetin $\mathrm{H}$, or $10 \mu \mathrm{M}$ Bay 11-7082 for $1 \mathrm{~h}$ and stimulated with $1 \mu \mathrm{g} / \mathrm{ml}$ LPS for $30 \mathrm{~min}$. Bay 11-7082 is a compound that inhibits IKK $\alpha / \beta$ and I $\kappa \mathrm{B} \alpha$ phosphorylation and was used as a positive control (RauertWunderlich et al., 2014). Treated cells were fixed, permeabilized, blocked, and stained with NFкB (p65) primary antibody, Dylight 488 conjugated secondary antibody, and Hoechst 33342 dye, sequentially. The Hoechst and DyLight fluorophores detect changes in nuclear morphology (blue fluorescence) and NF- $\kappa$ B distribution (green fluorescence), respectively. Nuclear Translocation Bioapplication software on the Arrayscan VTI reader was used for image acquisition and analysis (Thermo Fisher Scientific, Waltham, MA, USA). For each well, at least 400 cells were automatically acquired and analyzed. The translocation index was calculated by measuring the average intensity difference of NF- $\kappa \mathrm{B}$ between the identified cytoplasmic and nuclear regions.

\subsection{Western Blot Analysis}

Differentiated THP-1 cells were pretreated with various concentrations of cis-gnetin H, transgnetin $\mathrm{H}$, or $10 \mu \mathrm{M}$ Bay 11-7082 for $1 \mathrm{~h}$ and stimulated with $1 \mu \mathrm{g} / \mathrm{ml}$ PS for $15 \mathrm{~min}$. Cells were lysed with radio-immunoprecipitation assay (RIPA) lysis buffer that contained a protease and phosphatase inhibitor cocktail. Cell lysates were then tested for protein concentration using a 
BCA protein assay and diluted with RIPA lysis buffer to normalize protein concentrations. Lysates were mixed with sample loading buffer containing bromophenol blue, glycerol, sodium dodecyl sulfate (SDS), and 2-mercaptoethanol. The separated proteins were then transferred onto a nitrocellulose membrane and blocked with 5\% nonfat-dried milk in $1 \mathrm{X}$ Tris-buffered saline (TBS) with $0.1 \%$ Tween-20 for $30 \mathrm{~min}$. The blots were incubated with primary antibodies for p65, phosphorylated p-65 (Ser536), IKK $\beta$, phosphorylated IKK $\alpha / \beta$ (Ser176/180), IкB $\alpha$, and phosphorylated IкB $\alpha(\operatorname{Ser} 32)$ at $4{ }^{\circ} \mathrm{C}$ overnight or for $1 \mathrm{~h}$ at $22^{\circ} \mathrm{C}$ followed by incubation with HRP-conjugated secondary antibodies for $1 \mathrm{~h}$ at $22^{\circ} \mathrm{C}$. The membranes were then developed by addition of ECL substrate, and images were collected by ChemiDoc XRS+ system chemiluminescence imager (Bio-Rad, Hercules, CA, USA).

\subsection{Statistical Analysis}

All experiments were conducted at least three times independently. Western blot band intensity analysis was performed using image lab software (Bio-Rad, Hercules, CA, USA) and statistical significance of concentration-response curves and the $\mathrm{IC}_{50}$ calculation were determined by GraphPad Prism version 6.0 (GraphPad, La Jolla, CA, USA). Numeric values of treated groups were compared to the control group, and results were expressed as the mean \pm SEM. Statistical significance was analyzed using one-way analysis of variance followed by a Sidak test. A $p$ value $<0.05$ was considered significant.

\section{Results}

\subsection{Cytotoxicity of Cis-and Trans-Gnetin-H on PMA-Differentiated THP-1 Macrophages}

Prior to the cytokine measurements, we assessed cell viability using Alamar Blue and CellGlow ${ }^{\circledR}$ luminescent assays to ensure cells were viable for the duration of the treatments. Pretreatment of cells with cis-gnetin $\mathrm{H}$ at 13, 25, or $50 \mu \mathrm{M}$ followed by $20 \mathrm{ng} / \mathrm{ml}$ LPS had no significant effect on cell viability relative to the LPS alone control with both viability methods

(Fig. 2). However, cells pretreated with trans-gnetin $\mathrm{H}$ at $50 \mu \mathrm{M}$ showed less than $90 \%$ viability relative to the LPS alone control; therefore, concentrations of, 8,15 , and $30 \mu \mathrm{M}$ trans-gnetin $\mathrm{H}$ were used for the cytokine response assay.The vehicle control, DMSO, at all of the concentrations tested showed no adverse effects on cell viability (data not shown). 


\subsection{The Effects of Cis- and Trans-Gnetin H on TNF- $\alpha, I L-1 \beta$, and IL-8 Response in LPS-}

Stimulated THP-1 Cells

We then investigated the effects of cis- and trans-gnetin $\mathrm{H}$ on expression of the inflammatory cytokines TNF- $\alpha$, IL-1 $\beta$, and IL-8 in LPS-induced THP-1 macrophages. The graphs shown in Figure 3 show that LPS at a concentration of $20 \mathrm{ng} / \mathrm{ml}$ increased the expression of TNF- $\alpha$, IL-1 $\beta$, and IL-8. The DMSO, at all concentrations tested, did not affect the cytokine response in LPStreated THP-1 cells (data not shown). Dexamethasone (positive control) at a concentration of 1 $\mu \mathrm{M}$ showed $58 \%, 56 \%$, and $63 \%$ inhibition of TNF- $\alpha$, IL-1 $\beta$, and IL-8, respectively. Cells treated with cis-and trans-gnetin H showed significant inhibition of TNF- $\alpha$, IL-1 $\beta$, and IL-8 $(\mathrm{p}<0.05)$. We then measured the concentration of cis-and trans-gnetin $\mathrm{H}$ that inhibited $50 \%$ of TNF- $\alpha\left(\mathrm{IC}_{50}\right)$ and found $\mathrm{IC}_{50}$ values of $19 \mu \mathrm{M}$ for cis-gnetin $\mathrm{H}$ and $6 \mu \mathrm{M}$ for trans-gnetin $\mathrm{H}$ (Fig. 4).

\subsection{The Effects of Cis- and Trans-Gnetin H on NF-кB Transcription Factor Nuclear Translocation}

We next examined the effects of cis- and trans-gnetin $\mathrm{H}$ on NF- $\mathrm{NB}$ nuclear translocation by targeting p65 (RelA), which is a significant transcription factor in the canonical NF- $\mathrm{B}$ pathway. As Fig. 5A shows, p65 (green fluorescence) remained in the cytoplasm in untreated cells, whereas p65 translocated into the nucleus in LPS-challenged cells. Bay 11-7082 inhibited the p65 nuclear translocation, and both cis- and trans-gnetin $\mathrm{H}$ inhibited p65 nuclear translocation, as shown in Fig. $5 \mathrm{~A}$ and $\mathrm{B}$.

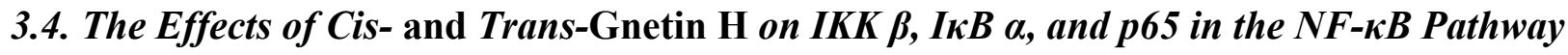

We also measured LPS-induced activation of important mediators in the NF- $\kappa \mathrm{B}$ pathway,IKK $\beta$, I $\kappa \mathrm{B} \alpha$, and $\mathrm{p} 65$. Our results showed that in LPS-stimulated cells, I $\mathrm{B} \alpha$ phosphorylation was also significantly inhibited by the two compounds in a concentration-dependent manner (Fig. 6A). p65 phosphorylation was only significantly inhibited by cis-gnetin $\mathrm{H}$ at the highest concentration $(50 \mu \mathrm{M})$, but both 15 and $30 \mu \mathrm{M}$ trans-gnetin $\mathrm{H}$ showed significant inhibition of $\mathrm{p} 65$ phosphorylation in a concentration-dependent manner. IKK $\beta$ phosphorylation was also significantly inhibited by cis- and trans-gnetin H (Fig. 6C). 


\section{Discussion}

Inflammation is an important component of a healthy immune response, yet it is also associated with serious human diseases. Many inflammatory diseases do not have effective treatments for control of chronic inflammation. Currently available preventive therapies for chronic inflammatory and autoimmune diseases block the cytokine response, particularly TNF- $\alpha$, which is the most important cytokine involved in the inflammatory response(Bradley, 2008).Anti-TNF therapy has been clinically demonstrated as the most effective approach to control inflammation (Postal and Appenzeller, 2011). Cytokines that are released by immune cells, such as TNF- $\alpha$, play a critical role in inflammatory processes by inducing chemotaxis, activation of various types of cells, and amplification of inflammation (Thalayasingam and Isaacs, 2011; Yamamoto and Gaynor, 2001a). The present study demonstrates that cis-and trans-gnetin H can effectively suppress the expression and release of LPS-induced cytokines, TNF- $\alpha$, IL-1 $\beta$, and IL- 8 , from PMA-differentiated human THP-1 cells in a concentration-dependent manner without toxicity (Fig. 2 and 3). It is notable that the two compounds effectively suppress not only TNF- $\alpha$ but also interleukins. This suggests that the compounds isolated from the seeds of Paeonia suffruticosa exert their inhibitory effects in a broad manner through suppressing the intracellular NF- $\kappa \mathrm{B}$ signaling pathway, which regulates TNF- $\alpha$, IL-1 $\beta$, and IL-8; the regulation of these cytokines by cis- and trans-gnetin $\mathrm{H}$ is important because they are considered the most important proinflammatory cytokines in human disease pathogenesis(Hiscott et al., 1993; Kunsch and Rosen, 1993; Shakhov et al., 1990). It is notable that the activity levels stimulated by the two compounds were significantly different. The $\mathrm{IC}_{50}$ values of $c i s$ - and trans-gnetin $\mathrm{H}$ for inhibition of TNF- $\alpha$ activity show that trans-gnetin $\mathrm{H}$ is greater than three-fold more efficient than cisgnetin $\mathrm{H}$ at inhibiting TNF- $\alpha$ (Fig. 4). The only difference between the structures of the two compounds is the stereochemistry of the $\mathrm{C}-7^{\prime} / \mathrm{C}-8$ 'olefinic moiety, which is the aromatic ring structure containing a hydroxyl group. (Gao et al., 2015). It may be worth determining if the difference in biological activity is attributable to the effect of the hydroxyl group or olefin position.

$\mathrm{NF}-\kappa \mathrm{B}$ pathway activation is among the most complex proinflammatory pathways, and it is an essential pathway resulting in massive production of proinflammatory cytokines (Yamamoto and Gaynor, 2001a; Yamamoto and Gaynor, 2001b). To promote transcription and production of 
proinflammatory cytokines, NF-אB must be translocated into the nucleus(Fujita et al., 1992; Lee

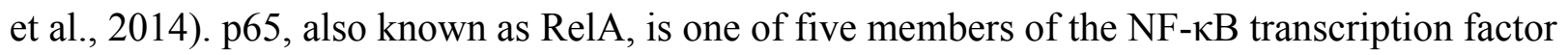
family and is the most abundant and critical factor of the canonical NF- $\kappa$ B pathway (Sasaki et al., 2005; Schmitz and Baeuerle, 1991; Yang et al., 2003).Studies have shown that the production of the TNF- $\alpha$ is strongly correlated with p65 nuclear translocation (Sung et al., 2014), and our data suggest that the non-toxic levels of cis-and trans-gnetin $\mathrm{H}$ effectively blocked translocation of p65 to the nucleus, which is consistent with our cytokine results (Fig. 5). To investigate whether the attenuation of the p65 in the cytoplasm is upstream of the p65 phosphorylation or activation, we further explored the effects of cis-and trans-gnetin $\mathrm{H}$ on activation of key mediators of NF$\kappa \mathrm{B}$ pathway that lie upstream of p65 nuclear translocation.

$\mathrm{I} \kappa \mathrm{B} \alpha$ is aNF- $\kappa \mathrm{B}$ antagonist that binds to the homodimer or heterodimer of NF- $\kappa \mathrm{B}$, preventing the complex from translocating into the nucleus (Ganchi et al., 1992). To investigate the effect of p65 cytoplasm attenuation, we first determined the activation of I $\kappa \mathrm{B} \alpha$ by measuring phosphorylated I $\mathrm{KB} \alpha$, and we found that the $\mathrm{p}-\mathrm{I} \kappa \mathrm{B} \alpha$ expression was significantly suppressed by both cis-and trans-gnetin H (Fig. 6A). These data suggest that the attenuation of p65 in the cytoplasm is due to the antagonistic effect of IкB $\alpha$. We also investigated phosphorylation of p65, which is important in nuclear transport and transactivation(Viatour et al., 2005), and observed suppressed phosphorylation (Fig. 6B). This led us to investigate the activation of IKK- $\beta$, the kinase that phosphorylates both IкB $\alpha$ and p65 (Sizemore et al., 2002; Yang et al., 2003). As shown by our data, IKK- $\beta$ phosphorylation was significantly blocked by both cis-and transgnetin H (Fig. 6C), which suggests that compounds exert inhibition at the level of kinases that activate IKK through phosphorylation or direct inhibition of IKK- $\beta$ activation. The exact mechanism of LPS-induced IKK- $\beta$ phosphorylation is unclear; however, IKK- $\beta$ activation is required to activate the NF- $\mathrm{BB}$ pathway in LPS-induced macrophages (Israel, 2010; Li et al., 1999). Studies have suggested IKK- $\beta$ as a potential therapeutic target for multiple diseases involving chronic inflammation such as asthma (Catley et al., 2005), bone diseases (Ruocco and Karin, 2005), and obesity (Arkan et al., 2005).

Macrophages are the initial inflammatory regulator and therefore,suppressing macrophage activation can alleviate inflammatory responses and slow the severity of disease progression caused by chronic inflammation. Our results suggest that cis-and trans-gnetin H compounds can 
significantly limit the cytokine response in human THP-1 macrophages through suppressing the activation of IKK- $\beta$, which is the most attractive target for suppression of the NF- $\kappa$ B pathway (Tak and Firestein, 2001). Recently, great attention has been given to the derivatives of resveratrol in medicinal and food chemistry as alternatives to overcome the poor bioavailability of resveratrol due to its rapid metabolism in vivo which compromises the biological and pharmacological benefits (Neves et al., 2012). According to recently published study on pharmacokinetics of resveratrol derivatives in humans, dimer derivatives of resveratrol which include gnetin $\mathrm{C}$ compounds, showed increased bioavailability by oral administration compared to the resveratrol monomer (Tani et al., 2014). Therefore, cis-and trans-gnetin H, which are trimers of resveratrol, may be worth investigating for their bioavailability through oral consumption. Experiments are in progress to better understand the mechanism and target for these compounds. In conclusion, we suggest cis-and trans-gnetin $\mathrm{H}$ have potential pharmacological benefits for treating diseases and conditions that involve chronic inflammation.

\section{Acknowledgments}

We would like to acknowledge funding from the National Science Foundation (grant 0841370) Tennessee Center for Botanical Medicine Research (TCBMR), the Molecular Biosciences doctoral program and the Biology Department at Middle Tennessee State University (MTSU) for providing the funding for this study.

\section{References}

Abraham, S. M., T. Lawrence, A. Kleiman, P. Warden, M. Medghalchi, J. Tuckermann, J. Saklatvala, and A. R. Clark, 2006, Antiinflammatory effects of dexamethasone are partly dependent on induction of dual specificity phosphatase 1: J Exp Med, v. 203, p. 1883-9.

Aggarwal, B. B., 2003, Signalling pathways of the TNF superfamily: A double-edged sword: Nature Reviews Immunology, v. 3, p. 745-756.

Aggarwal, B. B., A. Bhardwaj, R. S. Aggarwal, N. P. Seeram, S. Shishodia, and Y. Takada, 2004, Role of resveratrol in prevention and therapy of cancer: preclinical and clinical studies: Anticancer Res, v. 24, p. 2783-840.

Aminoshariae, A., J. C. Kulild, and M. Donaldson, 2016, Short-term use of nonsteroidal antiinflammatory drugs and adverse effects: An updated systematic review: J Am Dent Assoc, v. 147 , p. $98-110$.

Arkan, M. C., A. L. Hevener, F. R. Greten, S. Maeda, Z. W. Li, J. M. Long, A. Wynshaw-Boris, G. Poli, J. Olefsky, and M. Karin, 2005, IKK-beta links inflammation to obesity-induced insulin resistance: Nat Med, v. 11, p. 191-8. 
Bezalel, S., I. Asher, D. Elbirt, and Z. M. Sthoeger, 2012, Novel biological treatments for systemic lupus erythematosus: current and future modalities: Isr Med Assoc J, v. 14, p. 508-14.

Bjarnason, I., J. Hayllar, A. J. MacPherson, and A. S. Russell, 1993, Side effects of nonsteroidal anti-inflammatory drugs on the small and large intestine in humans: Gastroenterology, v. 104, p. 1832-47.

Bongartz, T., A. J. Sutton, M. J. Sweeting, I. Buchan, E. L. Matteson, and V. Montori, 2006, Anti-TNF Antibody Therapy in Rheumatoid Arthritis and the Risk of Serious Infections and Malignancies: Systematic Review and Meta-analysis of Rare Harmful Effects in Randomized Controlled Trials: JAMA, v. 295, p. 2275-2285.

Bozimowski, G., 2015, A Review of Nonsteroidal Anti-inflammatory Drugs: Aana j, v. 83, p. 425-33.

Bradley, J. R., 2008, TNF-mediated inflammatory disease: J Pathol, v. 214, p. 149-60.

Catley, M. C., J. E. Chivers, N. S. Holden, P. J. Barnes, and R. Newton, 2005, Validation of IKK beta as therapeutic target in airway inflammatory disease by adenoviral-mediated delivery of dominant-negative IKK beta to pulmonary epithelial cells: Br J Pharmacol, v. 145, p. 114-22.

Chanput, W., J. J. Mes, and H. J. Wichers, 2014, THP-1 cell line: an in vitro cell model for immune modulation approach: Int Immunopharmacol, v. 23, p. 37-45.

Choi, H. S., H. S. Seo, J. H. Kim, J. Y. Um, Y. C. Shin, and S. G. Ko, 2012, Ethanol extract of paeonia suffruticosa Andrews (PSE) induced AGS human gastric cancer cell apoptosis via fas-dependent apoptosis and MDM2-p53 pathways, J Biomed Sci, v. 19: England, p. 82.

Diamantopoulos, A. P., A. I. Larsen, and R. Omdal, 2013, Is it safe to use TNF-alpha blockers for systemic inflammatory disease in patients with heart failure? Importance of dosage and receptor specificity: Int J Cardiol, v. 167, p. 1719-23.

Fujita, T., G. P. Nolan, S. Ghosh, and D. Baltimore, 1992, Independent modes of transcriptional activation by the p50 and p65 subunits of NF-kappa B: Genes Dev, v. 6, p. 775-87.

Ganchi, P. A., S. C. Sun, W. C. Greene, and D. W. Ballard, 1992, I kappa B/MAD-3 masks the nuclear localization signal of NF-kappa B p65 and requires the transactivation domain to inhibit NF-kappa B p65 DNA binding: Mol Biol Cell, v. 3, p. 1339-52.

Gao, Y., C. He, R. Ran, D. Zhang, D. Li, P. G. Xiao, and E. Altman, 2015, The resveratrol oligomers, cis- and trans-gnetin $\mathrm{H}$, from Paeonia suffruticosa seeds inhibit the growth of several human cancer cell lines: J Ethnopharmacol, v. 169, p. 24-33.

He, C. N., Y. Peng, L. J. Xu, Z. A. Liu, J. Gu, A. G. Zhong, and P. G. Xiao, 2010, Three new oligostilbenes from the seeds of Paeonia suffruticosa, Chem Pharm Bull (Tokyo), v. 58: Japan, p. 843-7.

Hiscott, J., J. Marois, J. Garoufalis, M. D'Addario, A. Roulston, I. Kwan, N. Pepin, J. Lacoste, H. Nguyen, G. Bensi, and et al., 1993, Characterization of a functional NF-kappa B site in the human interleukin 1 beta promoter: evidence for a positive autoregulatory loop: Mol Cell Biol, v. 13, p. 6231-40.

Hu, S., G. Shen, W. Zhao, F. Wang, X. Jiang, and D. Huang, 2010, Paeonol, the main active principles of Paeonia moutan, ameliorates alcoholic steatohepatitis in mice, $\mathrm{J}$ Ethnopharmacol, v. 128: Ireland, 2009 Elsevier Ireland Ltd, p. 100-6.

Israel, A., 2010, The IKK complex, a central regulator of NF-kappaB activation: Cold Spring Harb Perspect Biol, v. 2, p. a000158. 
Kunsch, C., and C. A. Rosen, 1993, NF-kappa B subunit-specific regulation of the interleukin-8 promoter: Mol Cell Biol, v. 13, p. 6137-46.

Lee, R. E., S. R. Walker, K. Savery, D. A. Frank, and S. Gaudet, 2014, Fold change of nuclear NF-kappaB determines TNF-induced transcription in single cells: Mol Cell, v. 53, p. 86779.

Li, Z. W., W. Chu, Y. Hu, M. Delhase, T. Deerinck, M. Ellisman, R. Johnson, and M. Karin, 1999, The IKKbeta subunit of IkappaB kinase (IKK) is essential for nuclear factor kappaB activation and prevention of apoptosis: J Exp Med, v. 189, p. 1839-45.

Manna, S. K., A. Mukhopadhyay, and B. B. Aggarwal, 2000, Resveratrol suppresses TNFinduced activation of nuclear transcription factors NF-kappa B, activator protein-1, and apoptosis: potential role of reactive oxygen intermediates and lipid peroxidation: $\mathrm{J}$ Immunol, v. 164, p. 6509-19.

Mercurio, F., H. Zhu, B. W. Murray, A. Shevchenko, B. L. Bennett, J. Li, D. B. Young, M. Barbosa, M. Mann, A. Manning, and A. Rao, 1997, IKK-1 and IKK-2: cytokine-activated IkappaB kinases essential for NF-kappaB activation: Science, v. 278, p. 860-6.

Neves, A. R., M. Lucio, J. L. Lima, and S. Reis, 2012, Resveratrol in medicinal chemistry: a critical review of its pharmacokinetics, drug-delivery, and membrane interactions: Curr Med Chem, v. 19, p. 1663-81.

Oh, G. S., H. O. Pae, B. M. Choi, S. Jeong, H. Oh, C. S. Oh, Y. D. Rho, D. H. Kim, M. K. Shin, and H. T. Chung, 2003, Inhibitory effects of the root cortex of Paeonia suffruticosa on interleukin-8 and macrophage chemoattractant protein-1 secretions in U937 cells, J Ethnopharmacol, v. 84: Ireland, 2002 Elsevier Science Ireland Ltd., p. 85-9.

Postal, M., and S. Appenzeller, 2011, The role of Tumor Necrosis Factor-alpha (TNF-alpha) in the pathogenesis of systemic lupus erythematosus: Cytokine, v. 56, p. 537-43.

Rauert-Wunderlich, H., D. Daniela Siegmund, E. Maier, T. Giner, R. C. Bargou, H. Wajant, and T. Stühmer, 2014, The IKK Inhibitor Bay 11-7082 Induces Cell Death Independent from Inhibition of Activation of NFאB Transcription Factors.

Ruocco, M. G., and M. Karin, 2005, IKK \{beta $\}$ as a target for treatment of inflammation induced bone loss: Ann Rheum Dis, v. 64 Suppl 4, p. iv81-5.

Sasaki, C. Y., T. J. Barberi, P. Ghosh, and D. L. Longo, 2005, Phosphorylation of RelA/p65 on serine 536 defines an I\{kappa\}B \{alpha\}-independent NF-\{kappa\}B pathway: J Biol Chem, v. 280, p. 34538-47.

Schmitz, M. L., and P. A. Baeuerle, 1991, The p65 subunit is responsible for the strong transcription activating potential of NF-kappa B: EMBO J, v. 10, p. 3805-17.

Shakhov, A. N., M. A. Collart, P. Vassalli, S. A. Nedospasov, and C. V. Jongeneel, 1990, Kappa B-type enhancers are involved in lipopolysaccharide-mediated transcriptional activation of the tumor necrosis factor alpha gene in primary macrophages: J Exp Med, v. 171, p. $35-47$.

Sizemore, N., N. Lerner, N. Dombrowski, H. Sakurai, and G. R. Stark, 2002, Distinct roles of the Ikappa B kinase alpha and beta subunits in liberating nuclear factor kappa B (NF-kappa B) from Ikappa B and in phosphorylating the p65 subunit of NF-kappa B: J Biol Chem, v. 277, p. 3863-9.

Sung, M. H., N. Li, Q. Lao, R. A. Gottschalk, G. L. Hager, and I. D. Fraser, 2014, Switching of the relative dominance between feedback mechanisms in lipopolysaccharide-induced NFkappaB signaling: Sci Signal, v. 7, p. ra6. 
Tak, P. P., and G. S. Firestein, 2001, NF-kappaB: a key role in inflammatory diseases: J Clin Invest, v. 107, p. 7-11.

Tani, H., S. Hikami, S. Iizuna, M. Yoshimatsu, T. Asama, H. Ota, Y. Kimura, T. Tatefuji, K. Hashimoto, and K. Higaki, 2014, Pharmacokinetics and safety of resveratrol derivatives in humans after oral administration of melinjo (Gnetum gnemon L.) seed extract powder: J Agric Food Chem, v. 62, p. 1999-2007.

Thalayasingam, N., and J. D. Isaacs, 2011, Anti-TNF therapy: Best Pract Res Clin Rheumatol, v. 25, p. 549-67.

Viatour, P., M. P. Merville, V. Bours, and A. Chariot, 2005, Phosphorylation of NF-kappaB and IkappaB proteins: implications in cancer and inflammation, Trends Biochem Sci, v. 30: England, p. 43-52.

Wang, Q., H. Kuang, Y. Su, Y. Sun, J. Feng, R. Guo, and K. Chan, 2013, Naturally derived antiinflammatory compounds from Chinese medicinal plants: Journal of Ethnopharmacology, v. 146, p. 9-39.

Yamamoto, Y., and R. B. Gaynor, 2001a, Role of the NF-kappaB pathway in the pathogenesis of human disease states: Curr Mol Med, v. 1, p. 287-96.

Yamamoto, Y., and R. B. Gaynor, 2001b, Therapeutic potential of inhibition of the NF-kB pathway in the treatment of inflammation and cancer: Journal of Clinical Investigation, $\mathrm{v}$. 107 , p. 135-142.

Yang, F., E. Tang, K. Guan, and C. Y. Wang, 2003, IKK beta plays an essential role in the phosphorylation of RelA/p65 on serine 536 induced by lipopolysaccharide: J Immunol, $\mathrm{V}$. 170, p. 5630-5.

Zhao, H., D. Yang, M. Shi, J. Liang, X. Yang, and S. Jin, 2014, Clinical efficacy and safety of traditional Chinese medicine combined with Western Medicine in patients with diabetic acute ischemic stroke: J Tradit Chin Med, v. 34, p. 145-9.

Figure 1. Chemical structures of cis-gnetin H (A) and trans-gnetin H (B).

Figure 2. Cytotoxicity of cis- and trans-gnetin H on PMA-differentiated THP-1 macrophages

PMA-differentiated THP-1 cells were treated with various concentrations of cis- and transgnetin $\mathrm{H}$ and tested for relative viability using the Alamar Blue assay (A) and luminescent assay (B). Cells were pretreated with 13, 25, $50 \mu \mathrm{M}$ cis-gnetin $\mathrm{H}$ or 8, 15, $30 \mu \mathrm{M}$ trans-gnetin $\mathrm{H}$ for $1 \mathrm{~h}$ followed by $20 \mathrm{ng} / \mathrm{ml}$ LPS for $4 \mathrm{~h}$ to determine relative \% viability against LPS control. The results are presented as the mean \pm SEM for triplicate measurements of at least three independent experiments.

Figure 3.Cis- and trans-gnetin H inhibits TNF- $\alpha$, IL-1 $\beta$, and IL-8 response in LPS-stimulated THP-1 cells 
PMA-differentiated THP-1 cells were pretreated with 13,25 , and $50 \mu \mathrm{M}$ cis-gnetin $\mathrm{H}$ or 8,15 , $30 \mu \mathrm{M}$ trans-gnetin $\mathrm{H}$ for $1 \mathrm{~h}$ and then stimulated with $20 \mathrm{ng} / \mathrm{ml} \mathrm{LPS} \mathrm{for} 4 \mathrm{~h}$. The secretion of TNF- $\alpha$ (A and B), IL-1 $\beta$ (C and D), and IL-8 (E and F) was determined by ELISA. The results are presented as the mean \pm SEM for triplicate measurements of at least three independent experiments. ${ }^{* *} \mathrm{p}<0.01,{ }^{* * *} \mathrm{p}<0.001,{ }^{* * * *} \mathrm{p}<0.0001$ compared with LPS-treated group.

Figure 4.Concentration-response curves of cis- and trans-gnetin $\mathrm{H}$ on TNF- $\alpha$

PMA-differentiated THP-1 cells were pretreated with increasing concentrations of cis- (A) and trans- (B)gnetin $\mathrm{H}$ for $1 \mathrm{~h}$ and then stimulated with LPS for $4 \mathrm{~h}$ Supernatants were tested for human TNF- $\alpha$ by ELISA. The concentration-response curve was plotted to determine $\mathrm{IC}_{50}$ values with GraphPad Prism version 6.0 software. The $\mathrm{IC}_{50}$ value of $c i s$-gnetin $\mathrm{H}$ was determined to be $19 \mu \mathrm{M}$ and $\mathrm{IC}_{50}$ value of trans-gnetin $\mathrm{H}$ was determined to be $6 \mu \mathrm{M}$.

Figure 5. The effects of cis- and trans-gnetin $\mathrm{H}$ on the NF- $\mathrm{kB}$ transcription factor nuclear translocation

PMA-differentiated cells were treated with cis- gnetin $\mathrm{H}$ at $50 \mu \mathrm{M}$, trans-gnetin $\mathrm{H}$ at $30 \mu \mathrm{M}$, or Bay 11-7082 at $10 \mu \mathrm{M}$ for $1 \mathrm{~h}$ and then stimulated with $100 \mathrm{ng} / \mathrm{ml}$ LPS for $30 \mathrm{~min}$. The transcription factor, p65, was stained with rabbit anti-p65 followed by Dylight 488-conjugated secondary antibody (green fluorescence) and Hoechst 33342 dye (blue fluorescence), sequentially (A). The numeric index of nuclear fluorescence of p65 was collected using Nuclear Translocation Bioapplication software on the Arrayscan VTI reader. The results are presented as the mean \pm SEM for triplicate measurements of at least three independent experiments. ${ }^{*} p<$ $0.05, * * * * \mathrm{p}<0.0001$ compared with LPS-treated group.(B).

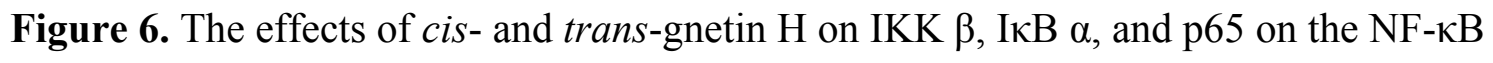
pathway

PMA-differentiated cells were pretreated with 13,25 , and $50 \mu \mathrm{M}$ cis-gnetin $\mathrm{H}$ and 8,15 , and 30 $\mu \mathrm{M}$ trans-gnetin $\mathrm{H}$ for $1 \mathrm{~h}$ and stimulated with $1 \mu \mathrm{g} / \mathrm{ml}$ LPS for $15 \mathrm{~min}$. Phosphorylated IкB $\alpha$ (Ser32) and total IкB $\alpha$ (A), phosphorylated p65 (Ser536) and total p65 (B), phosphorylated (Ser176/180) IKK- $\beta$ and total IKK- $\alpha \beta$ (C) were measured by western blotting. $\beta$-actin serves as 
loading control. Data are represented as the mean \pm SEM for at least three independent experiments. ${ }^{* *} \mathrm{p}<0.01,{ }^{* * *} \mathrm{p}<0.001,{ }^{* * * *} \mathrm{p}<0.0001$ compared with LPS-treated group. 


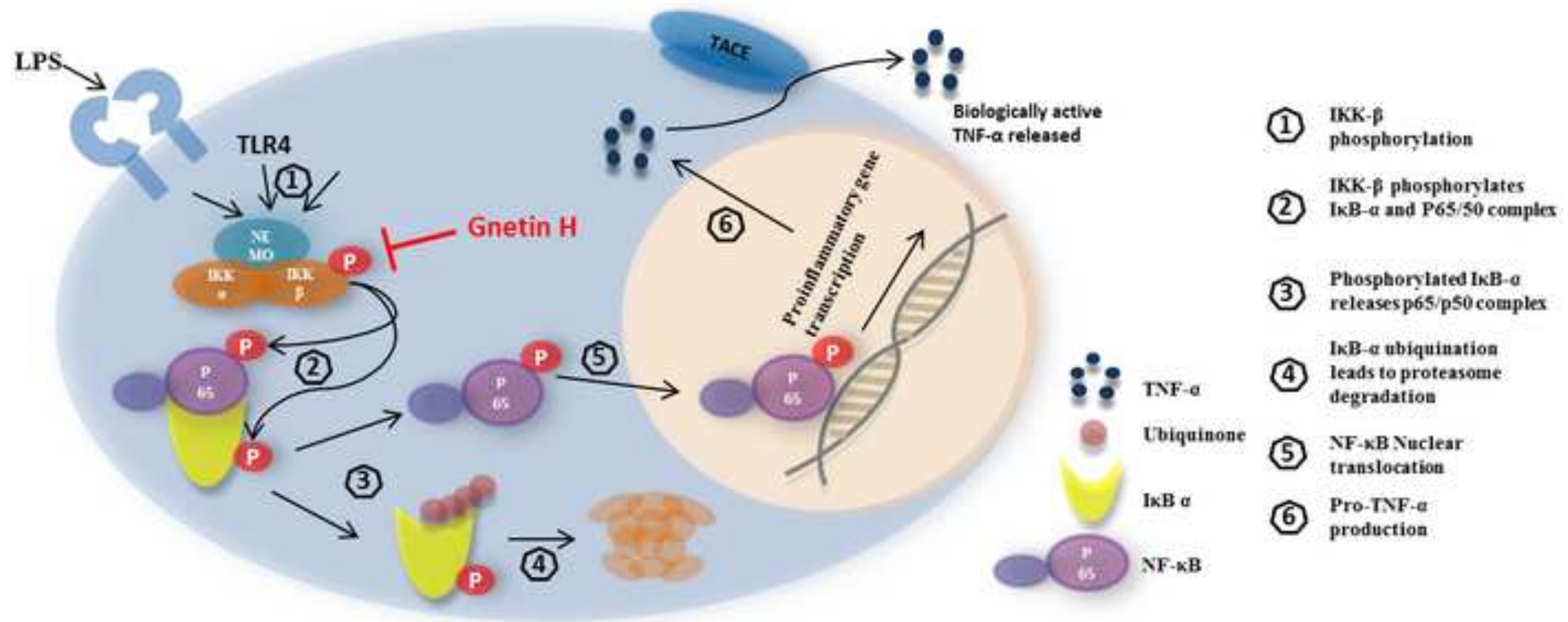


A

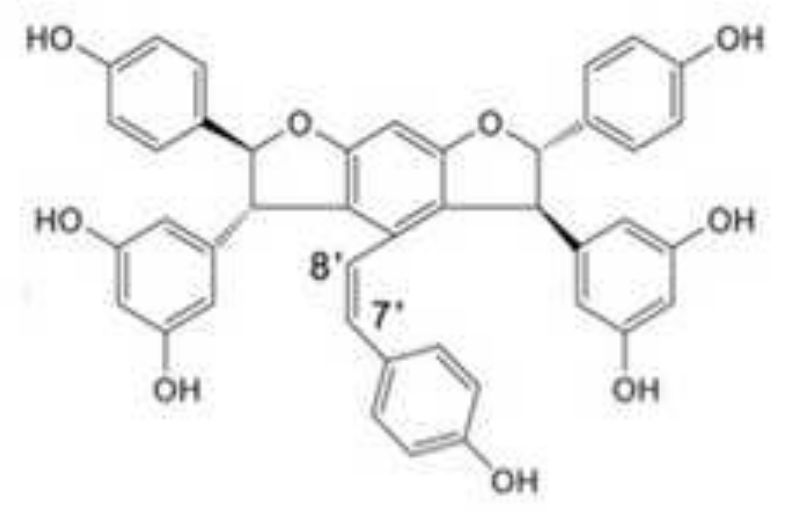
,
B

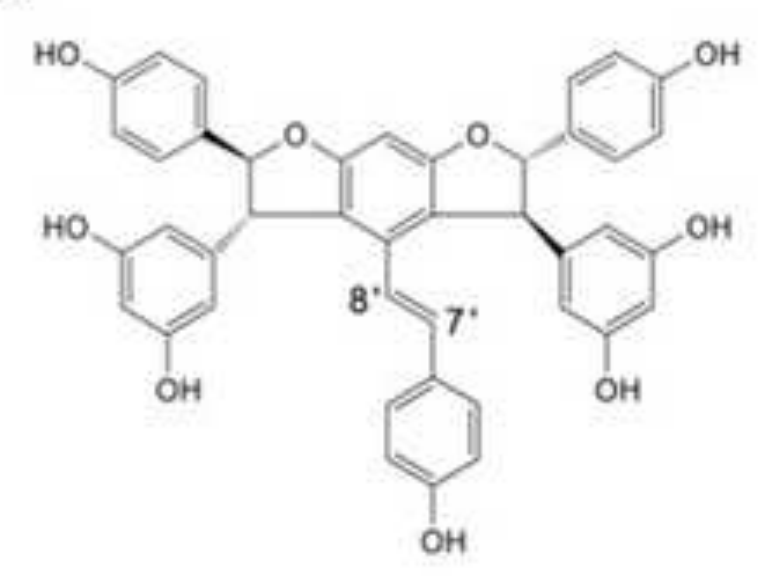


A

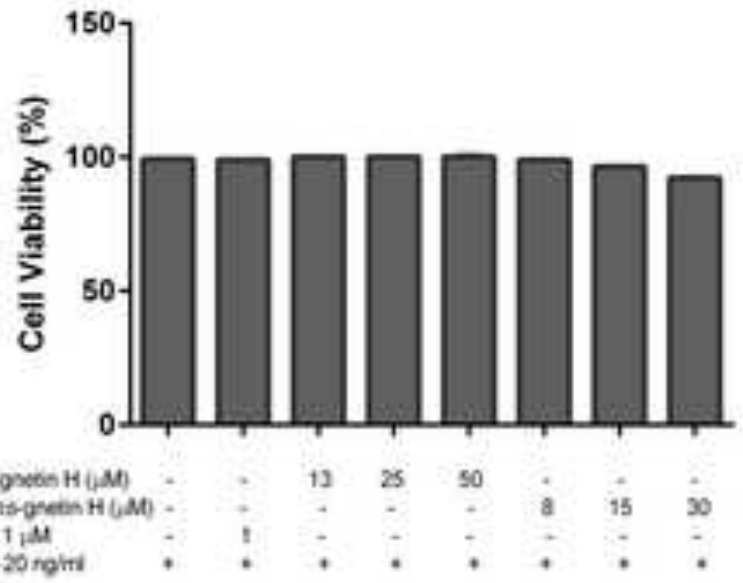

B

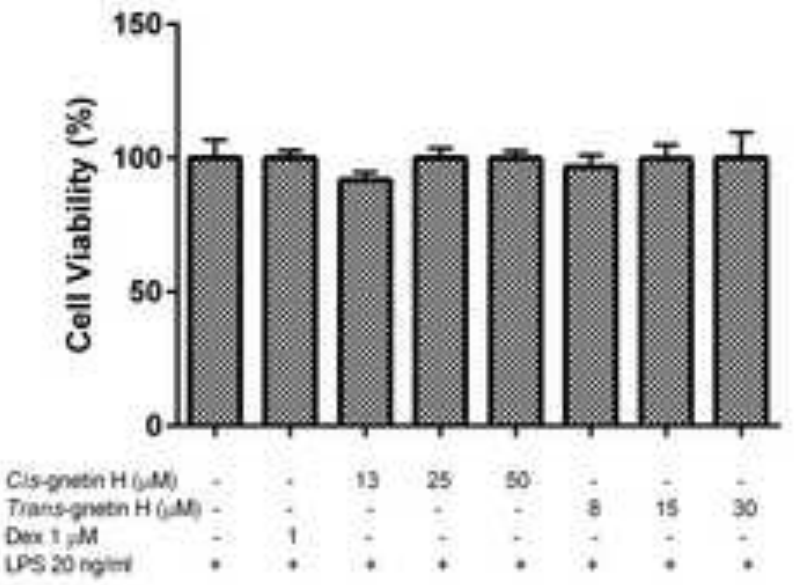


Figure 3

A

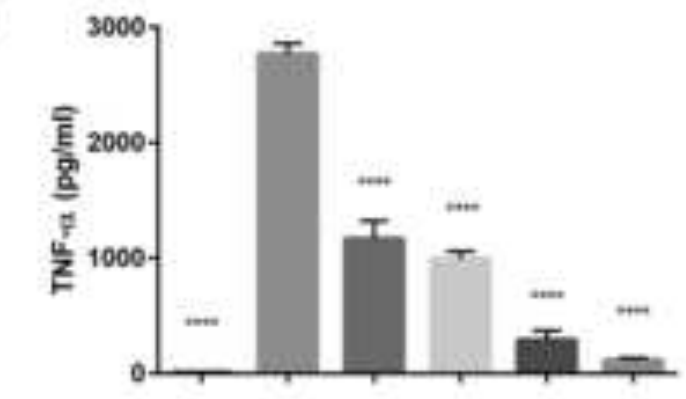

Cin-gnetin $M$ GNI Dext $\alpha M$

Les $20 \mathrm{ngimt}$

B

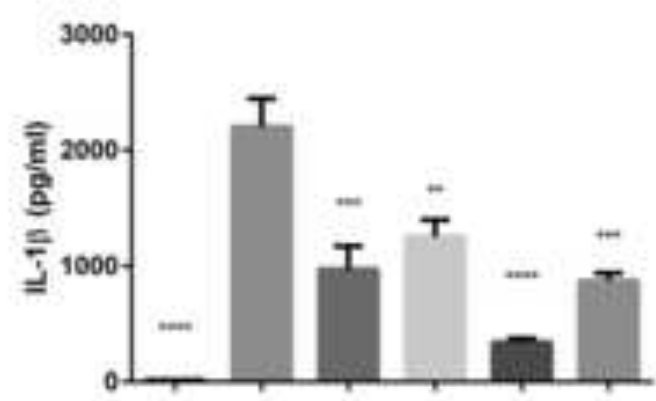

Chigneen $H(u M)$. Dex 1 in

LPS 20 nginal

C

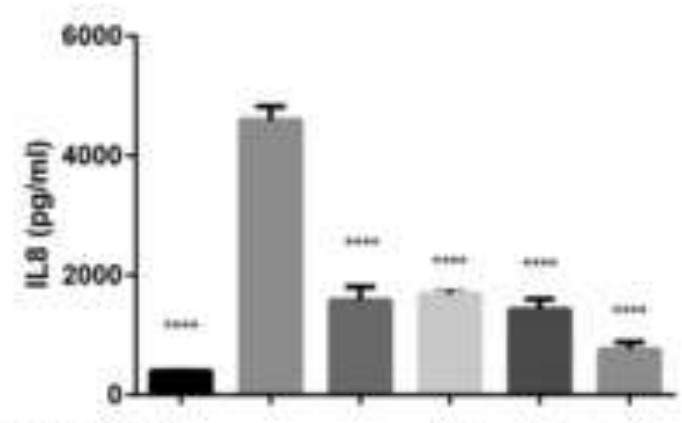

Cis-gnetin $H(6)$. Dex 1 u Les 20 ngim!
D

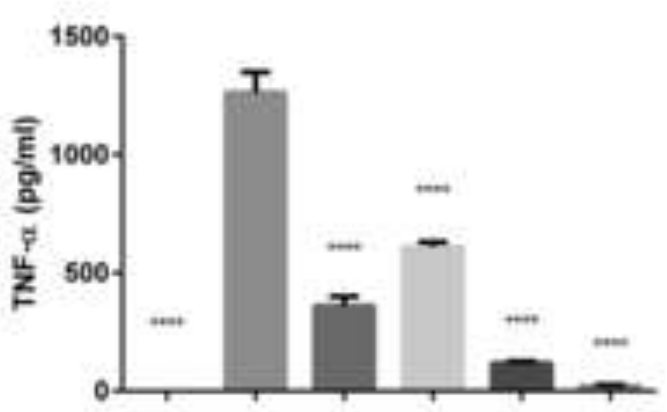

Trans-gnetin $H(6 \mathrm{M})$ Der 1 iM LPS 29 ngim!

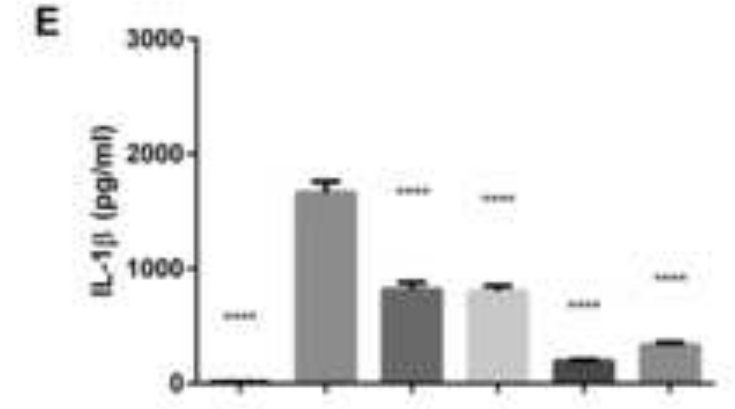

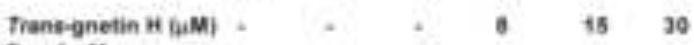
Dex 1 in M

Leg $20 \mathrm{ng}$ mi + + + + +

\section{F}

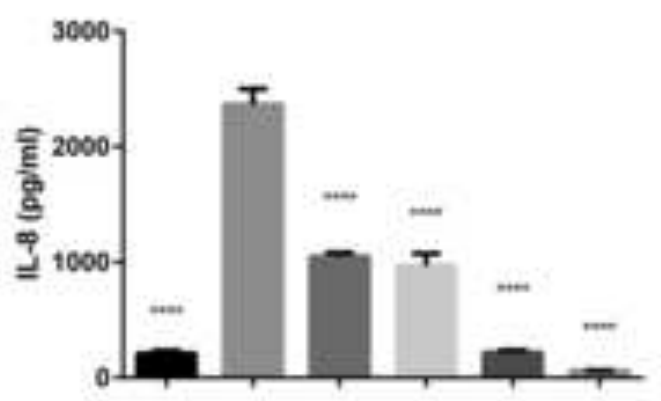

Trans-gnetin 14 (4, M)

Dex 7 uM

LPS at ngim! 
A

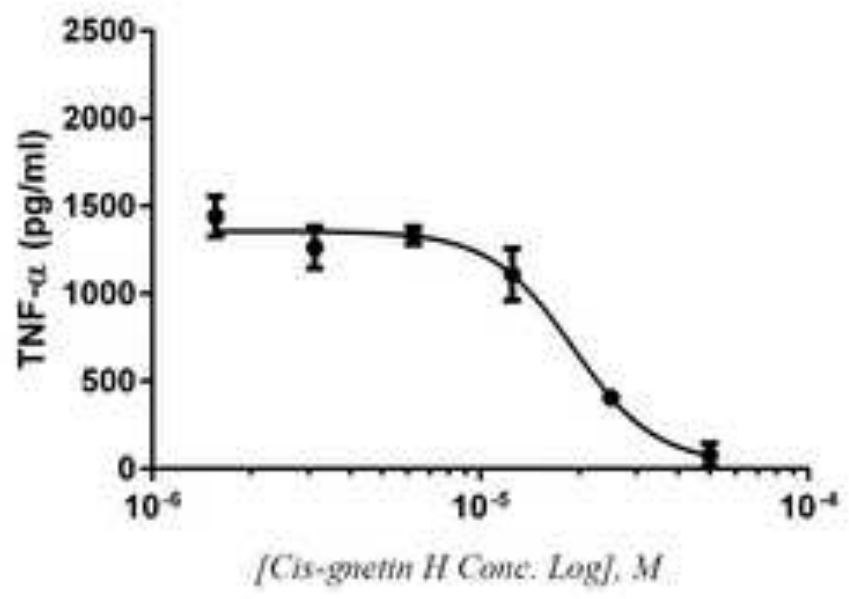

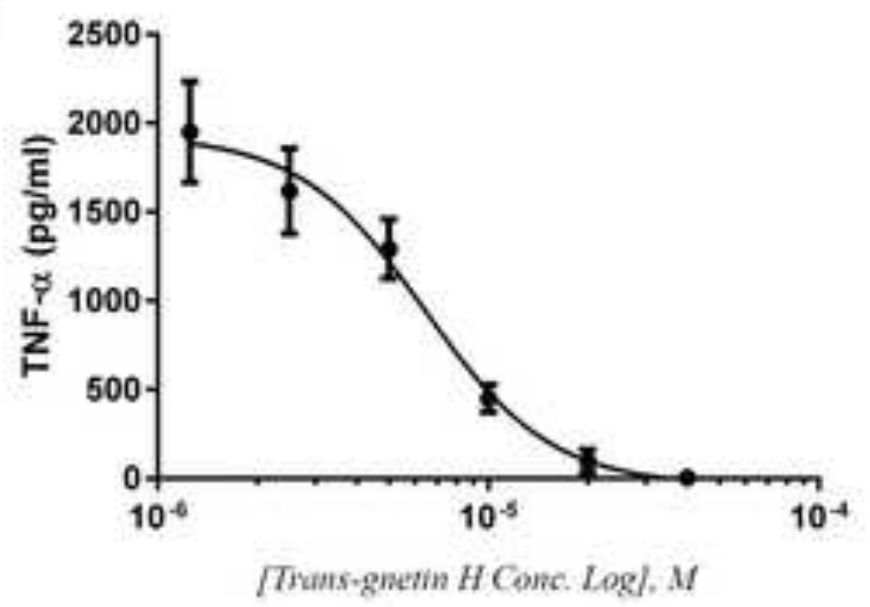

B 


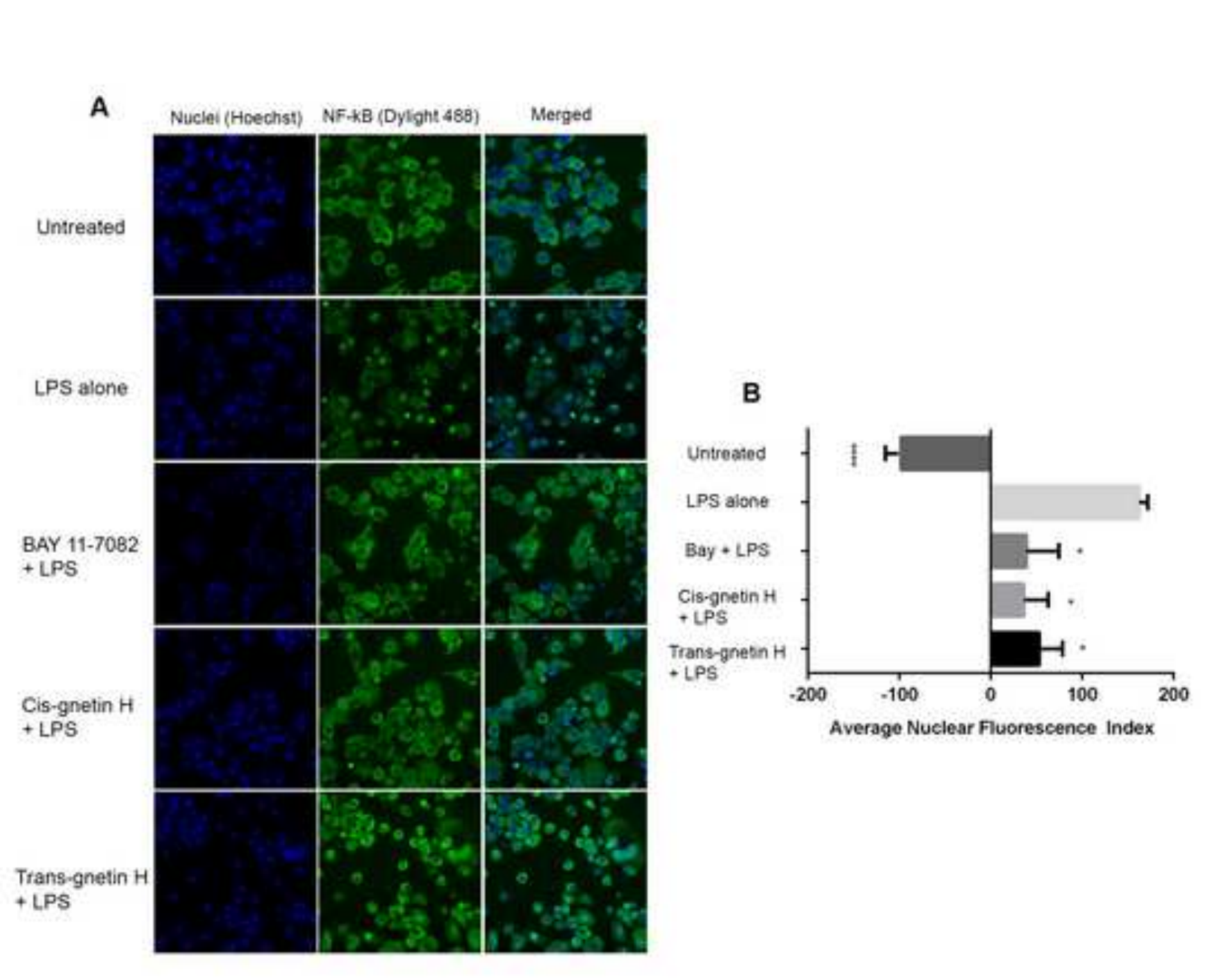

Figure 5

.

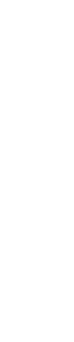




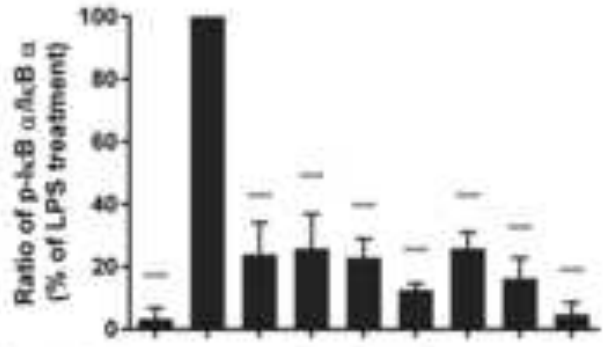

Cisgroten 24

Trans-gretn H. Bay
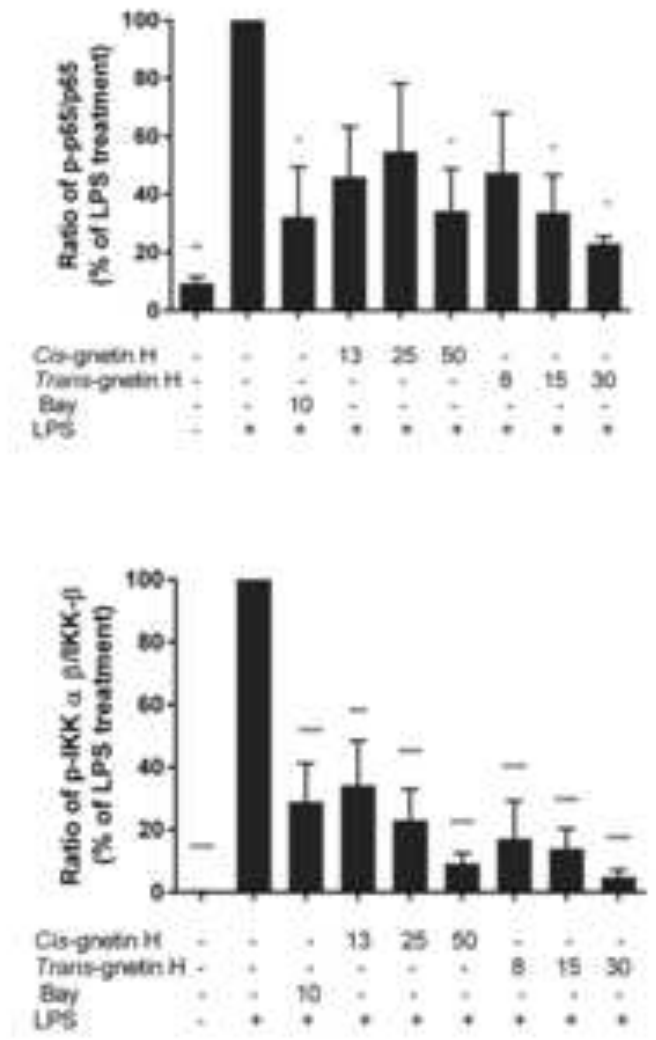

A

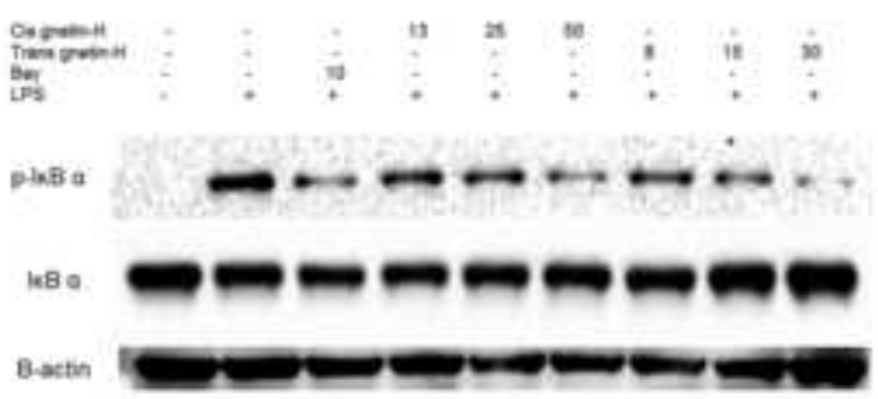

B

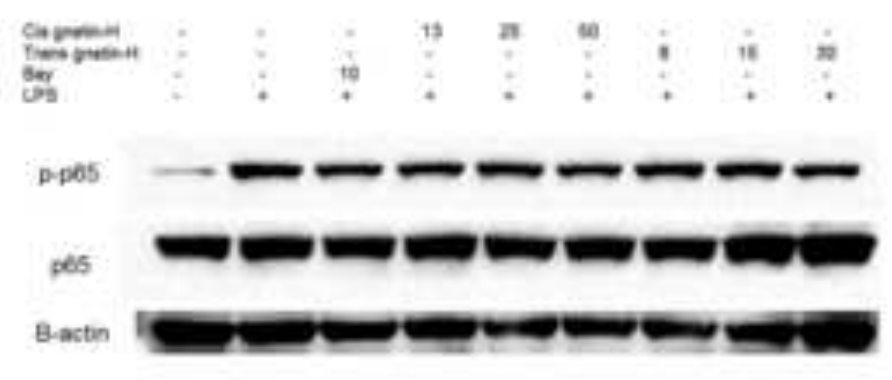

C

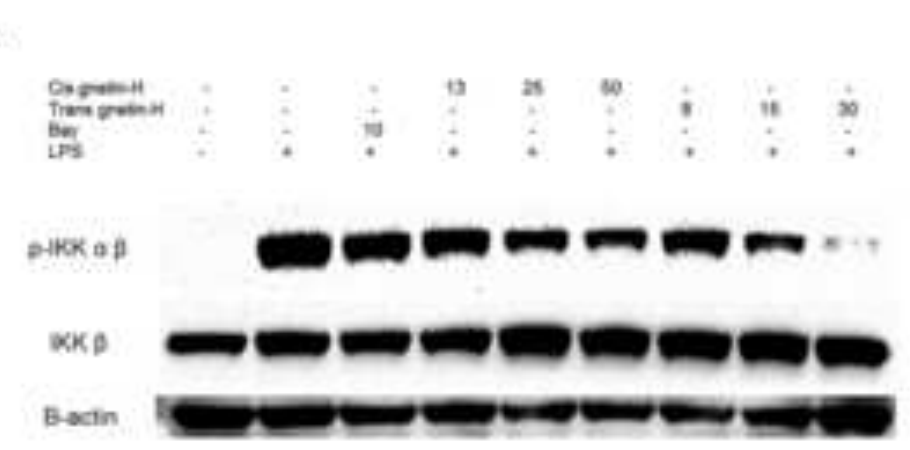

\section{Figure 6}

